\title{
Traditional Medicine as a Synergy to orthodox medicine in Dagbon Area of Ghana
}

\author{
Abdallah Iddrisu Yahaya ${ }^{1^{*}}$, David Millar ${ }^{2}$ \\ ${ }^{1}$ Senior Lecturer, University for Development Studies, UDS, Dept. Of Medicine and Allied Science, Clinician, \\ Tamale Teaching Hospital, Regional Tb, Clinician, Head of Chest Unit, Tamale Teaching Hospital (TTH) \\ Ghana \\ ${ }^{2}$ Doklah Kwame Anthony, Catholic University College of Ghana, Founder and President, Partners in \\ Information Technology (PIT)
}

*Corresponding Author: Abdallah Iddrisu Yahaya, Senior Lecturer, University for Development Studies, UDS, Dept. Of Medicine and Allied Science, Clinician, Tamale Teaching Hospital, Regional Tb, Clinician, Head of Chest Unit, Tamale Teaching Hospital (TTH) Ghana

\begin{abstract}
Utilization of traditional medical therapy dates back into antiquity; virtually, every culture in the world has relied on it to treat/prevent one ill-health or another. Despite the current advances in conventional health care, traditional medicine (TRM) use continues to upsurge at both local and global scales.

In this research work, qualitative and quantitative method (mixed method) approach was used to study traditional medicine as synergy to orthodox medicine at Dagbon area of Ghana. The research problem was that orthodox medicine alone has failed to control the burden of double disease pandemic in Northern Ghana.

Results of the study showed that Traditional medicine as synergy to orthodox medicine will make health care delivery in Dagbon area more of a success.
\end{abstract}

\section{INTRODUCTION}

The health of individuals, families and communities is a key issue in global development. Health problems are at the forefront of the national development agenda. It is an indicator of development and also the means to achieve a desired development. But for a country to grow, its population must be healthy and strong, and to be healthy calls for efficient and effective use of current health care facilities.

In his preface, Rosen (1958: 17) prescriptively states that "the protection and promotion of the health and well-being of its citizens are considered to be one of the most important roles of the modern state. This function is the quintessence of a public policy based on political, economic, social and ethical considerations. "Article 25 of the Universal Declaration of Human Rights (UDHR) explains that everyone has the right to a standard of living health and well-being, including food, medical care and the right to safety in the event of illness, debility and disability, so the right to good health care is not only an element essential for human existence, but also a major role of the government.

Studies have found that the economic development of a nation is not only a function of income or wealth, but also of other social services such as the improvement of health services. Human resources in organizations cannot function effectively at full capacity in the absence of effective and efficient health services. It is for this reason that the 1992 Constitution of the Republic of Ghana requires the Government to ensure sustainable socio-economic development of its citizens, without distinction as to class, ethnic origin, sex, age, religion or geographical location. ).

In this regard, the role of the health sector is to improve human capital - "create wealth through health" - and to develop and implement proactive policies to ensure the health and vitality of

The health status of a country's population affects the condition of the workforce, which determines production, while poor health has a serious impact on the education of children. Improving health would therefore result in significant savings on health care costs as a result of reducing the burden of 
disease. Healthy, strong, smart and active human capital will be more productive, creating more wealth and increasing the nation's Gross National Income (GNI). Burden of illness and deaths reported by preventable diseases such as malaria Cholera, HIV / AIDS and more are on the rise now, while health promotion mechanisms such as sanitation, personal hygiene, improved nutrition, good water sources, literacy, are in place.

In Ghana, primary health care (PHC) has been adopted as the strategy of the country's health delivery system to achieving health for all. Primary health care is part of the socio-economic development goals of ensuring equity in overall development efforts. This has become necessary because most Ghanaians live in rural areas. They produce most of the nation's food and cash crops for export.

The role played by the TRM system in ensuring quality of life with appropriate medications and the well-being of citizens and national economic, social and political growth is critical in developing economies. In this regard, WHO has officially recognized the importance of integrating TRM into health care systems at the World Health Assembly in 1977. This policy change was based on the fact that traditional medical care could be an additional resource for health care delivery (WHO, 1979). Full integration is essential in the delivery of comprehensive health care. Instinctively, the integration of medical systems should be guided by an understanding of the health seeking behavior and how the available medical modalities are used.

\section{BACKGROUND OF STUDY}

The Ghanaian health system has gone through a series of developments and revolutions since the accession to political independence. Nevertheless, like other developing countries, Dagbon Area is still struggling to find ways to provide an effective, efficient, appropriate and comprehensive health system for its ever-growing population. Preventable infectious diseases, which are the main cause of morbidity and mortality in the country, continue to affect the population.

With the double burden of emerging diseases and the escalating costs of health services, there is an urgent need to expand health services beyond orthodox medicine, especially to address the challenges posed by HIV / AIDS, HIV and AIDS.

The traditional medical system, designed according to the orthodox system of health care delivery, has been woefully inadequate to meet the basic health needs of citizens. Most Ghanaians do not have access to orthodox health care, especially in rural areas.

The spatial gap in access to health care is a major concern Ghana. It is largely demonstrated by unequal and differentiated distribution of health facilities between rural and urban division. Studies shows that more than $71 \%$ of health facilities, $85 \%$ of all physicians or physicians and their assistants in Ghana are concentrated in the regional capital (MOH / GHS, 2012, GSS, 2012) at the expense of rural areas. There is the problem of the unequal distribution of health structures between the urban core and the urban peripheries. In the Kumasi metropolis, for example, rural areas are lacking maternal and pediatric health services. So, women and children in the rural should go far to the center where such facilities are available.

Income has been identified as a major factor that forces the use of health care Services in Ghana (Buor, 2008a). High costs of imported drugs and the costs have made orthodox health care expensive and unattractive to the ordinary Ghanaian.

TRM is in harmony with people's personal values, religious and health philosophies (Osamor and Owumi, 2010, Bishop et al., 2007, Furnham and Forey, 1994, Vincent and Furnham, 1996, Moore et al, 1985) and the system is used in this way. With the current dispensation, influx and progress of the orthodox medical system in Ghana, TRM continues to play an important role in Ghana's health system. To offer a clear and explicit elucidation of this phenomenon, the existing literature is desperate. Economic approaches are for the most part separated from anthropological perspectives. Thus, economic work is largely focused on accessibility, availability and accessibility.

Unfortunately, there is little information on the prognosticators of the use of TRMs in the northern sector since the subject is poorly empirically studied and defies documentation procedures. However, the factors that favour the choice and use of TRMs are unraveled elsewhere. Some studies associate the use of TRM with the socio-demographic and economic physiognomy of patients. 
Indeed, the conclusions of studies on the determinants of the use of TRMs plunge into perplexity. They are Mostly unpredictable and not well understood either. Keeping the point of view, investigating the determinants of TRM use in Ghana becomes relevant and therefore very clearly highlighted. The main objective of this study was to fill this research gap and enrich existing knowledge by analyzing the predictors of the use of TRMs in Ghana, taking Dagbon as a prefecture of study as evidence.

\section{RATIONAL OF THE STUDY}

It has been recognized that, as society's modernize they experience significant changes in their patterns of health care delivery. Despite rapid modernization across the globe, there are relatively few detailed case studies of changes in health care within specific countries especially for Sub Sahara Africa countries and for that matter the Dagbon Area of Ghana.

This research has been necessitated as a result of the need to integrate the traditional medicine into the orthodox medicine in Ghana. The reason being that traditional medicine by itself has some challenges in itself which the orthodox medicine can make up to. On the other hand, the orthodox medicine also has some challenges which the traditional medicine can make upto.

As a result, this research is to come help identify those weakness and challenges at both side and also suggest the possible ways of synergizing the two to achieve an optimal result in health care in and around the Dagbon area.

\section{LiTERATURE REVIEW}

According to Mahama Ibrahim 2014, medical knowledge started from the hunter and the fetish priest. He said, the fetish priest (Tindanba) got this knowledge from God but the hunters acquired the knowledge from animals in the bush by direct observation. The hunters observed the animals closely and found out which plants were eaten when ill. The knowledge obtained is then transferred on to humans when they are ill. The Dagbon traditional people believe and understand that this knowledge was obtained from God, therefore, can be relied upon. This is one of the major reasons why people of the Dagbon area will prefer using traditional medicine as against orthodox medicine.

From the accounts of AbayomiSofowora, man's symbolic relation over time with plants has given the world many invaluable benefits. Apart from the raw materials that go to form our variety of foods, the most important plant products are medicines, cosmetics and flavour products, as well as other pharmaceuticals.

Since ancient times, the early empirical observations of man have served as the basis for the preparation of cosmetics, drugs and pharmaceuticals, and finally the emergence of the modern pharmaceuticals, cosmetic and flavour industries. Evidence accruing from recent observations of animals show that even chimpanzees use a number of plant species for their medicinal value (Huffman and Wrangham, 1993). The development of prototype disciplines related to modern chemistry, pharmacy and botany enables the production of medical preparations from plant products on which the traditional medical system of the various geographical regions are based.

Traditional medicine is widespread throughout the world. At its general program of work meeting covering the period 1990-1995, the World Health Organization (WHO) redefined traditional medicine as comprising therapeutic practices that have been in existence, often for hundreds of years, before the development and spread of modern scientific medicine and still in use today. These practices vary widely, in keeping with the social and cultural heritage of different countries (WHO, 1991).

In a study on the lay representation of chronic diseases in Ghana (de Graft Aikins et al. 2012) drawing participants from both rural and urban settings in Ghana found that multiple causal theories were presented for most of the common chronic diseases in Ghana especially for diabetes and hypertension. Cancers were attributed to toxic foods while asthma was attributed to environmental pollution. Epilepsy and sickle cell diseases were believed to have spiritual roots. In their conclusion, they noted that lay representations of common chronic diseases and their major risk factors in Ghana provide public health prevention strategies. This, according to them, raises two challenges: the need to train experts to provide accurate information in practical language that lay people can understand and apply to their daily lives and also to develop sustainable behaviour change interventions by drawing on best practices from other African countries. 
Kwame Abukari, a Graduate Student in his paper for Master in Indigenous Studies, University of Tromso, Norway, wrote that: Among the Dagombas of Ghana, what constitutes good health (alaafe) and illness (doro) are complex and hard to distinguish. According to their worldviews, health and illness are on a continuum. As Bierlich (2000:707) notes, "the Dagombas see many illnesses ... as inescapable facts of living and growing up. They demand no explanation, they are part of people's everyday experiences; they "come and go"'.

Dagombas theorized that certain illnesses are innate to us. People are born with them, live through them and die with them. As one of the traditional healers said; 'you see, illnesses such as chua Piles), kpaga (fever) and dirigu (Migraine) are part of us, indicating that, we come down to this earth with them. They are part of everyone's creation. They are in our blood'. This means that these illnesses are internal to the people. They are part of existence. They only become illnesses when triggered by other forces both within the individual body and the external worlds (physical, social, spiritual). Dagomba also know that other illnesses come to the body from the outside; hence they have complex explanatory models to illness causation. This notion is illustrated in the language when people say: Doro n-gbaii ma (translated as 'illness has catch me') which means that illness from the external worlds has come to the person. People never catch illnesses. Rather, it is the illness that catches them, thus come to come. A person can be ill $(N$ bera) or be under illness (baritim/barigu) but a person never catches illness ( $N$ gbaaidoro). Rather, it is the illness that catches or come to people (Doro $n$ gbaai $O$ ).

Therefore, for the Dagomba, good health (alaafe) is not an absence of illness. This resonates well with the WHO definition of health as "a state of complete physical, mental and social well-being and not merely the absence of disease or infirmity" (cited in Helman 2007:126-127). But the Dagomba conception of health goes beyond this. Their conception of good health (alaafee) is deep, complex, discursive and relational. It is deep, complex and relational in the sense that, the word alaafee signifies wellbeing and a state of balance with the self, others, the community and the spiritual world. This is reflected in the language as one of the participants claimed: Alaafeis an expression in the language and not necessarily being sick.

As a tradition, most traditional healers do not take money for providing traditional medicine and healing to their clients. This was reported by many of the traditional healers and confirmed by some of the consumers of traditional healing services. As one of the traditional healers said: Money weakens traditional medicine. Many have lost their healing powers because they now put money in front of their work. You can't sell traditional medicine and want it to work. I don't charge people for healing them. After healing or when the person gets well, anything he/she gives me is what I take. But I don't charge people.

This finding is similar to that of Bierlich (1999:320) as he discusses local healing and the use of money among Dagombas. He noted that among Dagombas, "herbalists are supposed to be spiritually and morally upright; otherwise their medicine will not work". The author also found that healers and everyone else in Dagbon (among the Dagombas) believe that charging money would weaken the power of their medicines. This perspective thus indicates that different approach should be used in seeking for medicine from healers. Accordingly, the most common approach then is to greet and ask for medicine ( $N$ puhekasuhitim) usually by the use of kola nuts.

Lastly, the paper has also pointed out some implications the Dagombas lay theories of illness and health may have on the people health seeking behaviours and called on western medical practitioners to be flexible and cultural sensitive when dealing with people with different lay theories, beliefs and knowledge about illnesses and health or who have different language and cultural background as theirs. These implications and recommendations when taken could help to reduce conflicts between patients and medical practitioners during healthcare service delivery especially within the western medical system.

\section{Methodology}

1. Mixed method (qualitative and quantitative approach) of Research was used for the study.

2. Sample size of Five hundred (500) was used. This includes 475 residents and 15 herbalists and 10 orthodox health Practitioners. 
3. Snore ball approach was used to identify the Traditional Hospitals at Five Villages.

4. At each village, focus group discussions were held with a minimum of five members for a period of 30 days.

\section{DISCUSSION OF FINDINGS}

The analysis of the data is done according to the research objectives. The first objective of the study was to analyze the extent to which people attend or use herbal medicine in the Dagbon area. The second was to explore the perceptions of the effectiveness of herbal medicine compared to orthodox medicine. The third was also to discover the basic characteristics of people who use herbal medicine and the conditions under which they use it. The ultimate goal was to explore the possibility of integrating traditional and orthodox health systems and the prospects for such integration.

Table1. Socio-demographic background of the residents

\begin{tabular}{|c|c|c|}
\hline Variable & Frequency & Percentage (\%) \\
\hline $\begin{array}{l}\text { Sex } \\
\text { Male } \\
\text { Female }\end{array}$ & $\begin{array}{l}81 \\
394 \\
\end{array}$ & $\begin{array}{l}17.1 \\
83 \\
\end{array}$ \\
\hline $\begin{array}{l}\text { Age group } \\
18-30 \\
31-40 \\
41-50 \\
51 \text { and above } \\
\end{array}$ & $\begin{array}{l}132 \\
194 \\
109 \\
40\end{array}$ & $\begin{array}{l}27.8 \\
40.9 \\
23 \\
8.4\end{array}$ \\
\hline $\begin{array}{l}\text { Marital status } \\
\text { Single } \\
\text { Married } \\
\text { Divorced } \\
\text { Widowed } \\
\end{array}$ & $\begin{array}{l}74 \\
344 \\
27 \\
30 \\
\end{array}$ & $\begin{array}{l}15.6 \\
72.4 \\
5.7 \\
6.3 \\
\end{array}$ \\
\hline $\begin{array}{l}\text { Religious Affiliation } \\
\text { Christianity } \\
\text { Islam } \\
\text { Traditional } \\
\text { Other } \\
\end{array}$ & $\begin{array}{l}143 \\
290 \\
39 \\
3 \\
\end{array}$ & $\begin{array}{l}30.1 \\
61.1 \\
8.2 \\
0.6\end{array}$ \\
\hline $\begin{array}{l}\text { Level of Education } \\
\text { No formal education } \\
\text { Primary } \\
\text { Junior High/Middle School } \\
\text { Senior High/Vocational School } \\
\text { Tertiary }\end{array}$ & $\begin{array}{l}110 \\
65 \\
155 \\
94 \\
51\end{array}$ & $\begin{array}{l}23.2 \\
13.7 \\
32.7 \\
19.8 \\
10.8\end{array}$ \\
\hline $\begin{array}{l}\text { Employment status } \\
\text { Employed } \\
\text { Unemployed }\end{array}$ & $\begin{array}{l}320 \\
155\end{array}$ & $\begin{array}{l}67.3 \\
32.7\end{array}$ \\
\hline $\begin{array}{l}\text { Average monthly Income } \\
\text { Below } \mathrm{GH} \phi 51 \\
\mathrm{GH} \phi 51-100 \\
\mathrm{GH} \phi 101-200 \\
\mathrm{GH} \phi 200-500 \\
\mathrm{GH} \phi 501 \text { and above }\end{array}$ & $\begin{array}{l}245 \\
75 \\
60 \\
50 \\
45\end{array}$ & $\begin{array}{l}51.6 \\
15.8 \\
12.6 \\
10.5 \\
9.5\end{array}$ \\
\hline $\begin{array}{l}\text { Place of Residence } \\
\text { Rural } \\
\text { Urban }\end{array}$ & $\begin{array}{l}334 \\
141\end{array}$ & $\begin{array}{l}70.3 \\
29.7\end{array}$ \\
\hline
\end{tabular}

Characteristic of the most disadvantaged districts of Ghana, a significant proportion of the population of Dagbon district resides in rural areas. About $70.3 \%$ of residents surveyed resided in rural areas, while $29.7 \%$ lived in urban areas of 10,000 or more inhabitants, as well as other urban characteristics such as health facilities, electricity, telephone and post, water This means that the patronage of herbal medicine would be high, since herbal medicine is readily available and easily accessible in rural areas.

Similarly, 9 of the 10 orthodox health professionals surveyed were women, while 2 were men. However, 14 of the 15 herbal practitioners interviewed were men, with only 1 being women. There are more women orthodox health professionals because most women are interested in the orthodox 
health care profession such as nursing, medical help and the profession of midwifery compared to traditional practice health care. In addition, more Orthodox practitioners were more willing to be interviewed than their male counterparts.

Four of the Orthodox health professionals interviewed were in the 31-40 age group and one was over 50 years old. In addition, 4 of the herbal practitioners surveyed were above the age of 50, with one person falling in the 18-30 age group. This implies that the practice of plants is not very attractive for young adults, but rather for the older generation, while the orthodox health profession seemed attractive to young people.

\subsection{Use of Herbal Medicine}

When respondents were asked which health care system they used the last time they were sick, $48.4 \%$ said they used medicinal plants, while $453 \%$ used orthodox drugs.But when asked what health care system they usually use when they are sick, $48.4 \%$ of those surveyed mentioned herbal medicine and 45.3 cited orthodox medicine.

\subsection{Usage of Herbal Medicine}

In addition, $24.9 \%$ of the users interviewed use herbal medicine "always or always", $41.5 \%$ use it "sometimes" but not always, $26.3 \%$ use it "from time to time" and only $7.3 \%$ "rarely or never" use herbal medicine. In addition, 9 of the 10 orthodox health professionals surveyed used herbal medicine "from time to time", with only I used it "sometimes" without anyone claiming to have "ever" used medicinal plants. This is indeed an obvious proof of the high patronage of herbal medicine, even among orthodox health professionals (doctors). This way of using herbal medicine was supported by the focus group responses. In general, most of them reported that herbal medicine was widely used in the study area.

Overall, $92.7 \%$ of users surveyed used herbal medicine at least once in their lifetime, while only $3.9 \%$ never used herbal medicine, but 3.4\% did not know if they had already used. To complete the high patronage of herbal medicine in the district is the fact that all 10 orthodox health professionals surveyed in the study also used herbal medicine at one time or another in their lives. In addition, 12 of the 15 herbalists surveyed confirmed that an average of 6 to 10 people patronized their services every day. This shows the high level of use of herbal medicine.

The main factor contributing to the growing popularity of plants in developed countries and their sustainable use in developing countries is the belief that they are effective and, in some cases, more effective than allopathic medicines. This favorable level of perceived efficacy supports their continued use, and in a significant number of patients, concomitant use with orthodox or allopathic medicines (Clement et al., 2007). In Dagbon District, herbal medicine is seen as effective in treatment.

Many diseases or conditions can be effectively treated with the roots, bark, leaves, fruits and flowers of plants. The study found that the common medical conditions under which herbal medicines are used include malaria, typhoid, jaundice, fever, infertility, sexual weakness, impotence, sexually transmitted diseases, diabetes and epilepsy. Others include piles, waist pain, menstrual pain, hernia, stroke, hypertension, tuberculosis, asthma, mental illness, arthritis, bone fracture, snake and dog bite, cutlass wound, boils and other skin infections.

\subsection{Common Medical Conditions Treated with Herbal Medicine}

According to results findings, piles and waist pains accounted for about $18.9 \%$ of the diseases that can be effectively treated with medicinal plants, infertility, sexual weakness, hernia and menstrual pain accounted for $14.2 \%$, Malaria, fever, typhoid and jaundice 14.7\% Percentage, boils and chronic skin infections accounted for 12.6 percent, and epilepsy and mental illness accounted for 9.2 percent.

Although most herbal practitioners in Dagbon District specialize in the diagnosis and treatment of diseases, some may be able to treat almost any disease. In all, about $15.8 \%$ of the herbal therapists surveyed treat infertility and sexual weakness, $11.6 \%$ treat malaria, fever, typhoid and jaundice, $18.9 \%$ treat hemorrhoids and waist pain, $10.7 \%$ treat boils and chronic skin infections and $9.8 \%$ sexually transmitted diseases. 


\section{CONCLUSION}

Analyzing the results of the findings, traditional and herbal medication is patronized by 54.7 percent of the people of Dagbon as against the orthodox which represents 45.3 percent.

Traditional Medicine must therefore be adopted as a synergy to orthodox Medicine to reduce the epidemic of double disease burden in Dagbon area.

\section{REFERENCES}

[1] Supports is highly needed by the Traditional healers as a benefits to the private public partnership policy to push the efficiency of the traditional healers.

[2] The orthodox medical will have to accept and upgrade the traditional healers to make health care system more of a success.

[3] The ministry of health must encourage further studies to aid in recognizing traditional healing as an accredited instituted to help increase access to good health care in Dagbbon area as policy makers.

[4] Freeman, M., and Motsei, M. (1992). Planning health care in South Africa: is there a role for traditional healers? SocSci Med, 34: 1183-1090.

[5] Freund, P. J. (1986). Health care in a Declining Economy: The Case of Zambia. Social Science and Medicine, 23(8), 75-88.

[6] Friedman, A. and Lahad, A. (2001). Health behaviour in a kibbutz population

[7] Gyasi, E., Agyepong, G. T., Ardayfio-Schandorf, E., Enu-Kwesi, E., Nabila, J. S. and Owusu-Bennoah, E. (1995). Production pressure and environmental change in the forest-savanna zone of Southern Ghana. Global Environmental Change, Volume 5, Issue 4, Pages 355-366.

[8] Gyasi, R. M., Tagoe-Darko, E. and Mensah, C. M. (2013). Use of Traditional Medicine by HIV/AIDS Patients in Kumasi Metropolis, Ghana: A Cross-sectional Survey. American International Journal of Contemporary Research, Vol. 3 No. 4.

[9] Gyasi, R. M., Mensah, C. M., Adjei, P. O and Agyemang, S. (2011). Public Perceptions of the Role of TRM in the Health care Delivery System in Ghana. Global Journal of Health Science: Vol. 3, No. 2; doi:10.5539/gjhs.v3n2p40.

[10] Harnack, L. J., Rydell, S. A. and Stang, J. (2001). Prevalence of Use of Herbal Products by Adults in the Minneapolis/St Paul, Minn, Metropolitan Area.Mayo Clinic Proceedings, Vol. 76, Issue 7; 688-694.

[11] Harris, P. and Rees, R. (2000). The prevalence of complementary and alternative medicine use among the general population: a systematic review of the literature. Complement TherMed , 8:88-96.

Citation: Abdallah Iddrisu Yahaya. "Traditional Medicine as a Synergy to orthodox medicine in Dagbon Area of Ghana" International Journal of Humanities Social Sciences and Education (IJHSSE), vol 5, no. 7, 2018, pp. 143-149 doi: http://dx.doi.org/10.20431/2349-0381.0507016.

Copyright: () 2018 Authors. This is an open-access article distributed under the terms of the Creative Commons Attribution License, which permits unrestricted use, distribution, and reproduction in any medium, provided the original author and source are credited. 